[Technical Paper]

\title{
X-ray Radiolysis-based Three Dimensional Additive Manufacturing Process
}

\author{
Shunya Saegusa*, Ikuya Sakurai**, Ikuo Okada**, Takao Fukuoka*, Satoru Suzuki*, Yuichi Utsumi*, \\ and Akinobu Yamaguchi* \\ *Laboratory of Advanced Science and Technology for Industry, University of Hyogo, Kamigori, Hyogo 678-1205, Japan \\ **Synchrotron Radiation Center, Nagoya University, Furo-cho, Chikusa-ku, Nagoya, Aichi 464-8603, Japan
}

(Received May 11, 2019; accepted October 29, 2019, published December 13, 2019)

\begin{abstract}
To achieve the three dimensional additive manufacturing process, we investigated X-ray radiolysis-induced photochemical reaction of $\mathrm{Cu}\left(\mathrm{CH}_{3} \mathrm{COO}\right)_{2}$ solution. Here, we demonstrated synthesis and immobilization of copper and copper oxide particles onto an aluminium substrate directly from the liquid solution. The particles are formed in the X-ray radiolysis of flowing aqueous solutions of $\mathrm{Cu}\left(\mathrm{CH}_{3} \mathrm{COO}\right)_{2}$ which also contain methanol as $\cdot \mathrm{OH}$ scavenger. We found that the sizes and compositions of the particles depend on the flow rate of solution. The results indicate that there are several routes and reaction processes for these particles formation and their aggregation. Our study will shed light on understanding and providing a novel photochemical reaction route induced under the X-ray irradiation. The development of X-ray radiolysis-induced photochemical reaction process enables us to achieve the rapid and easy formation of higher-order nano/ micro-scale structures consisting of composite materials.
\end{abstract}

Keywords: Three Dimensional Additive Process, Cupric Oxide, X-ray Radiolysis, Higher-order Structure, Synchrotron Radiation, Aggregation, Nano/micro Particles

\section{Introduction}

Three dimensional (3D) printing and additive manufacturing process have attracted much attention because of their easy and intriguing applicability and engineering applications.[1-3] There are a lot of methods and techniques which can create three dimensional structures made of plastic or metallic materials. Until now, there are few systems which can fabricate a structure consisting of composite materials such as metallic, plastic, and oxidized materials etc. One of the candidates which can achieve the formation of composite 3D structure is considered to be a system using photochemical reaction due to laser, [4, 5] $\gamma-[6]$ or X-ray radiolysis. [7-17]

In this study, we demonstrated the synthesis of nano/ micro-scale metallic particles and clusters onto an aluminium substrate including $\mathrm{Mg}$ as an impurity by the X-ray radiolysis-induced photochemical reaction combined with a fluidic channel at a synchrotron radiation (SR) facility because the advantage of performing X-ray radiolysisinduced photochemical reaction using SR is its atomic level of processing accuracy. Fine control and deep lithog- raphy are possible over irradiation parameters such as photon energy, band width, flux, polarization and elapsed time. Recently, Bhati et al.[15] and Yamaguchi et al.[12] have demonstrated that the synthesis of particles can be achieved by monochromatic X-ray irradiation in a metallic solution. Yamaguchi et al. also have fabricated caltropshaped cupric particles [14] and functional higher-order nanostructures[11] consisting of Au nanoparticles for the surface enhanced Raman scattering (SERS).[18] These studies open a door to investigate the physical-chemical reaction induced by the X-ray irradiation in the solution, and to develop a novel system for 3D structure formation and additive manufacturing process.

\section{Experimental}

A. X-ray irradiation of aqueous solution with a liquid flow system

We prepared copper (II) acetate $\left[\mathrm{Cu}\left(\mathrm{CH}_{3} \mathrm{COO}\right)_{2}\right]$ solution with an additive methanol in SR X-ray radiolysis experiments with a fluidic channel as schematically shown in Fig. 1. First, a liquid solution of $0.1 \mathrm{~mol} / \mathrm{L}$ (M) 


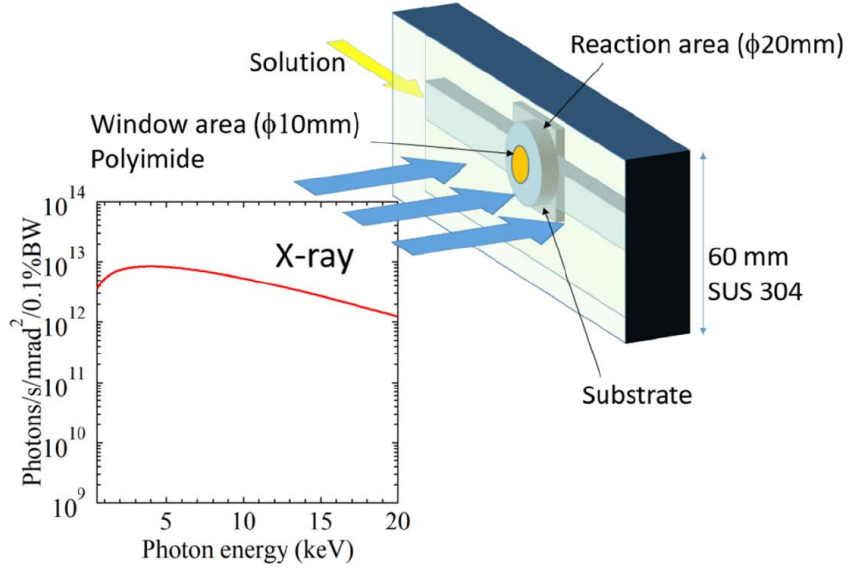

Fig. 1 Schematic of X-ray irradiation experiment at BL8S2, Aichi Synchrotron Center. The irradiation cell is connected to a liquid flow system. The liquid flow system can control the flow rate ranging from 1.0 to $75.0 \mathrm{~mL} / \mathrm{min}$.

$\left[\mathrm{Cu}\left(\mathrm{CH}_{3} \mathrm{COO}\right)_{2}\right]$ was prepared. Next, we added methanol into the $\left[\mathrm{Cu}\left(\mathrm{CH}_{3} \mathrm{COO}\right)_{2}\right]$ at a ratio of methanol : $\left[\mathrm{Cu}\left(\mathrm{CH}_{3} \mathrm{COO}\right)_{2}\right]=1: 20$ and prepared this mixed solution as the stock solution because no particles were synthesized and immobilized onto a substrate immersed in the aqueous $\left[\mathrm{Cu}\left(\mathrm{CH}_{3} \mathrm{COO}\right)_{2}\right]$ solution including of no additive. [14] We can control the flow rate ranging from 1 to $75 \mathrm{~mL} /$ min in the fluidic channel. Specimen such as aluminiumbased substrates were dipped in the X-ray irradiation cell, and irradiated by 5 minute X-ray ranging from about $7 \mathrm{keV}$ to $15 \mathrm{keV}$ as shown in Fig. 1. SR-induced X-ray radiolysis experiments were conducted using beam line BL8S2 at the Aichi Synchrotron Radiation Center, Aichi Science \& Technology Foundation. After the X-ray exposure, the specimen were washed with deionized water to remove residual materials which leaving the particles behind.

\section{B. Evaluation method}

The particles synthesized and immobilized onto the aluminium substrate were observed by a field emission electron microscopy (FE-SEM; JEOL JSM-7001F) with an energy dispersive X-ray analysis (EDX) to perform the element analysis. Micro-Raman spectroscopy was performed using the $532 \mathrm{~nm}$ wavelength as the excitation source by JASCO, NRS-5100. The power was set at $3.2 \mathrm{~mW}$ and a field lens with a magnification of 100 times was used. The diameter of the laser spot is about $1 \mu \mathrm{m}$. All experiments were performed at room temperature and in the ambient atmosphere.

\section{Results}

Figures 2(a) and 2(b) show the SEM images after 5 min. X-ray irradiation experiments conducted onto the alumin-
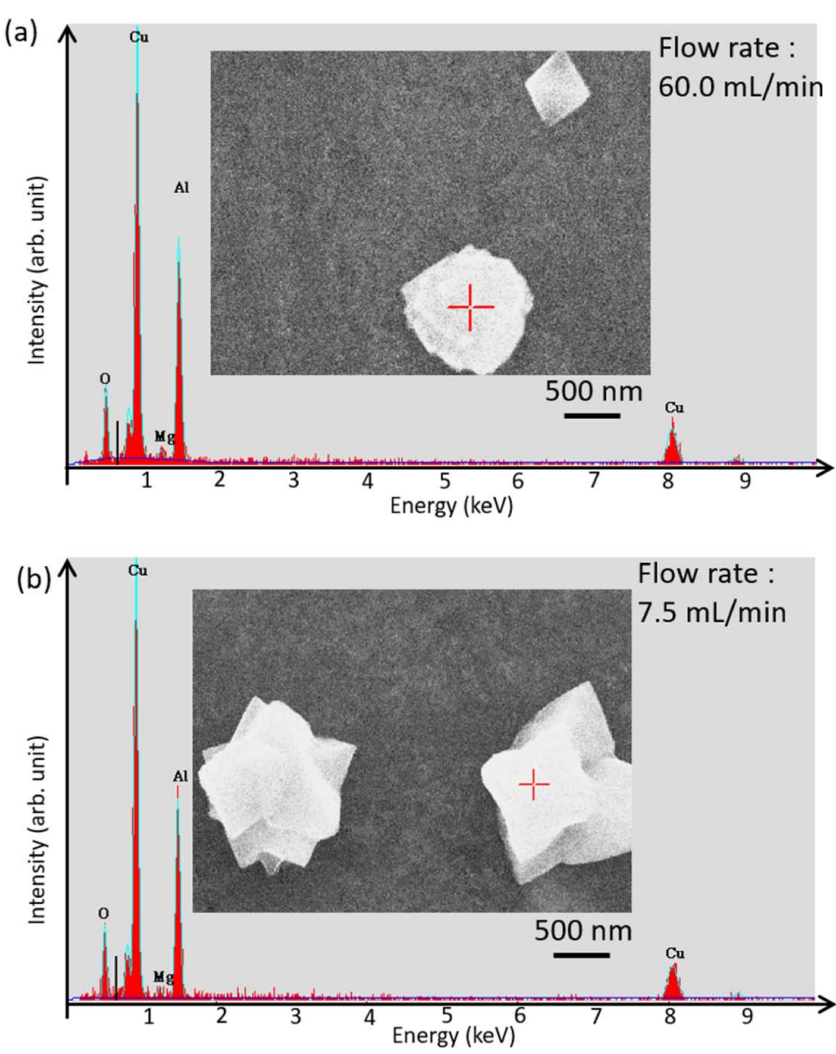

Fig. 2 SEM images and EDX analyses of particles synthesized by the $5 \mathrm{~min}$ X-ray irradiation with the liquid flow rates of 7.5 and $60.0 \mathrm{~mL} / \mathrm{min}$, respectively. The red crosses correspond to the points measured by the EDX analyzer. The scale bars in the SEM images are $500 \mathrm{~nm}$.

Table 1 Summary of EDX analysis in the case of the liquid flow rate of 60.0 and $7.5 \mathrm{~mL} / \mathrm{min}$.

\begin{tabular}{l|c|c}
\hline \multirow{2}{*}{ Element } & $\begin{array}{c}\text { Flow rate: } \\
\mathbf{6 0 . 0} \mathbf{~ m L / m i n}\end{array}$ & $\begin{array}{c}\text { Flow rate: } \\
\mathbf{7 . 5} \mathbf{~ m L / m i n ~}\end{array}$ \\
\cline { 2 - 3 } & At (\%) & At (\%) \\
\hline $\mathrm{O}(\mathrm{K})$ & 20.36 & 21.32 \\
\hline $\mathrm{Cu}(\mathrm{L})$ & 36.82 & 42.27 \\
\hline $\mathrm{Mg}(\mathrm{K})$ & 2.39 & 2.94 \\
\hline $\mathrm{Al}(\mathrm{K})$ & 40.42 & 38.20 \\
\hline
\end{tabular}

ium substrates with the liquid flow rates of 60.0 and 7.5 $\mathrm{mL} / \mathrm{min}$, respectively. As shown in Fig. 2, confection sugar particles and their aggregates are clearly observed. Here, we evaluated these particles by EDX to analyze the composition elements. The red solid crosses correspond to the points measured by EDX. By comparison of the element components summarized respectively in Table 1 , we found that those of the deposited particles are almost same while the particle sizes are different. The atomic $\%$ ratio of $\mathrm{Cu}: \mathrm{O}$ is about $2: 1$, indicating that the synthesized particles are cuprous oxide, $\mathrm{Cu}_{2} \mathrm{O}$. To obtain the deeper understanding 

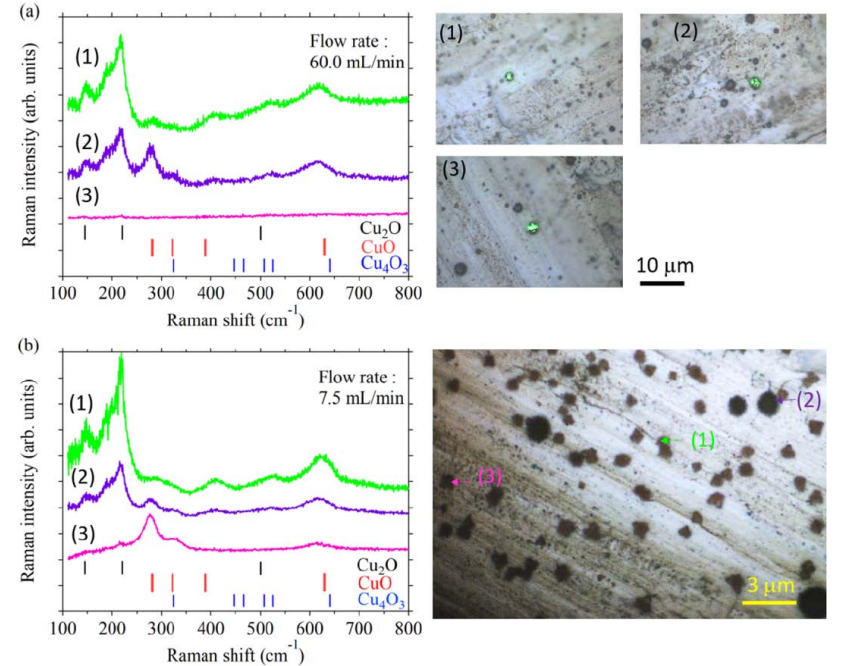

Fig. 3 Raman spectra of particles synthesized by the X-ray radiolysis with the flow rates of (a) 60.0 and (b) $7.5 \mathrm{~mL} / \mathrm{min}$, respectively. Numbered spectra are respectively measured from the corresponding particles shown in optical photographs.

the composition of the particles synthesized by the X-ray radiolysis-induced photochemical reaction, the microRaman spectroscopy was performed. Figures 3(a) and 3 (b) display the spectra of three particles synthesized when the flow rate of 60.0 and $7.5 \mathrm{~mL} / \mathrm{min}$, respectively. The optical photographs show the measurement points. Comparing the corresponding spectra, we found that the spectra are diverse. For example, the spectrum (3) in Fig. 3(a) is independent on Raman shift. The corresponding particle (3) is attributed to a metallic copper particle. According to previous studies[19-21] which reported Raman spectra of copper oxide materials, the particle (1) in Fig. 3(a) is expected to be almost $\mathrm{Cu}_{2} \mathrm{O}$ while the particle (2) is considered to be a mixture of $\mathrm{Cu}_{2} \mathrm{O}$ and $\mathrm{CuO}$. On the other hand, the main component of the particle (3) in Fig. 3(b) is expected to be $\mathrm{CuO}$. The particles (1) and (2) in Fig. 3(b) are almost similar with those in Fig. 3(a). The results indicate that various particles are synthesized and immobilized by the X-ray radiolysis-induced photochemical reaction in the fluidic solution. In our previous study[14] which the X-ray irradiation experiments were performed by a confinement cell, the main component of almost synthesized particles was considered to be $\mathrm{CuO}$ by EDX analysis and Raman spectroscopy. The differences are considered to be derived from the fluidic condition. The comparison of Figs. 3(a) and 3(b) alludes that the particle composition is determined by the ripening process dependent on the liquid flow rate to be discussed in discussion.

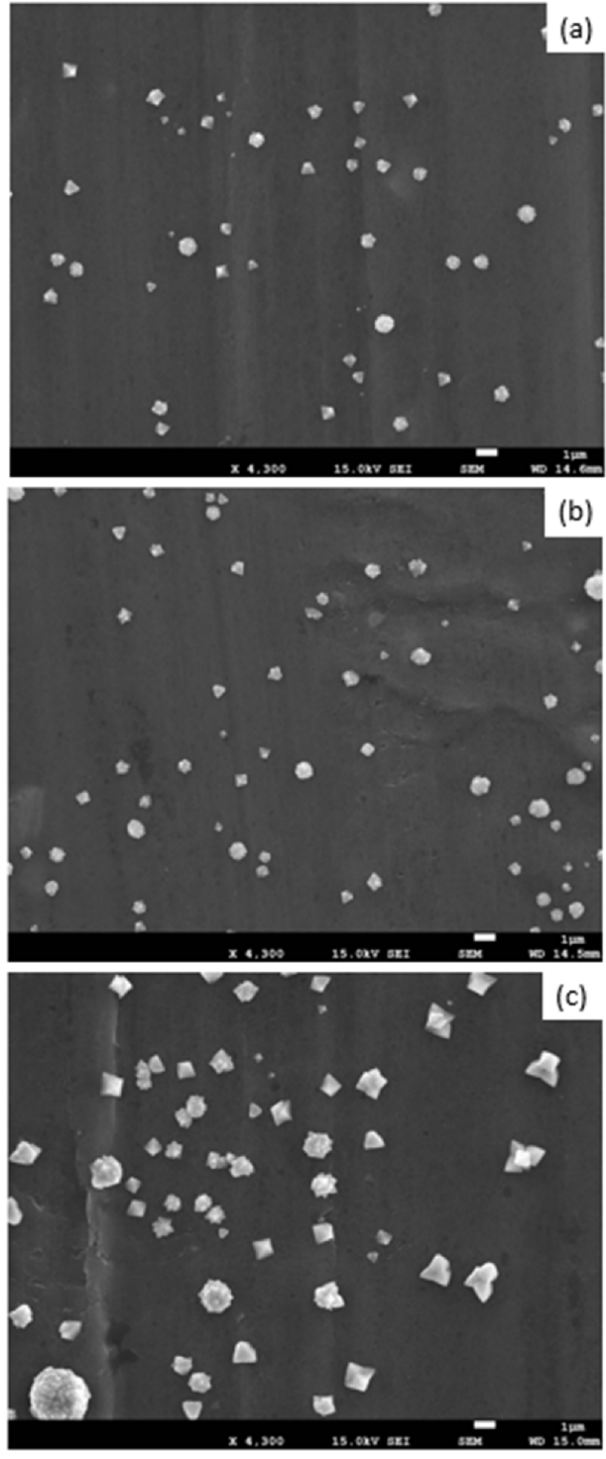

Fig. 4 SEM images of particles synthesized by the $5 \mathrm{~min}$ X-ray irradiation with the liquid flow rates of (a) 60.0, (b) 30.0, and (c) $7.5 \mathrm{~mL} / \mathrm{min}$, respectively. The scale bars in the SEM images are $1 \mu \mathrm{m}$.

Figures 4(a) - 4(c) display the SEM images of particles synthesized by the X-ray irradiation with the liquid flow rates of $60.0,30.0$, and $7.5 \mathrm{~mL} / \mathrm{min}$, respectively. As shown in these SEM images, the particle sizes trend to increase with decreasing the flow rate. To confirm it, the evaluation of particle size using the ImageJ[22] was performed. Figures 5(a) and 5(b) show the summary of the liquid flow rate dependence of the synthesized particle size and area ratio which is covered with the synthesized particles, respectively. It is found that the particle size clearly increases with decreasing the flow rate. The area ratio also increases with decreasing the flow rate. These results can provide a clue to understand the mechanism of these phenomena and to control and develop a novel process to three dimensional printing and additive manufacturing 

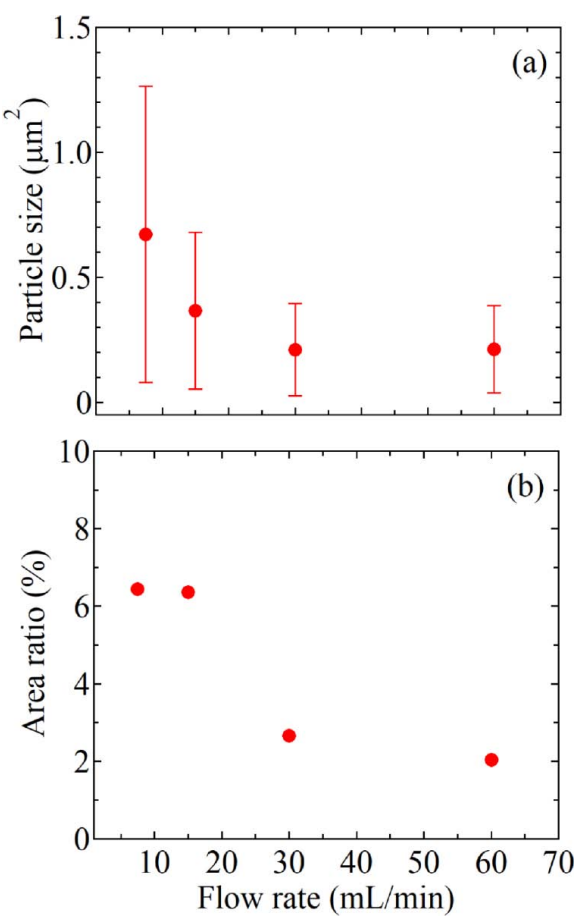

Fig. 5 Flow rate dependence of (a) synthesized particle average size and (b) Area ratio (\%) which is covered with the synthesized particles. Here, the error bars in (a) shows the standard deviation.

combined with electroplating.

\section{Discussion}

First, we consider that the physical and chemical mechanism of nucleation and growth of confection sugar shaped particles. The X- or $\gamma$-ray irradiation from the SR provides hydrate electrons, hydroxyl and hydrogen radicals etc. in the following manner:[23-25]

$$
\mathrm{H}_{2} \mathrm{O} \stackrel{\mathrm{X} \text {-ray }}{\longrightarrow} \mathrm{e}_{\mathrm{aq}}^{-}, \cdot \mathrm{H}, \cdot \mathrm{OH} \text {, etc. }
$$

Here, $\mathrm{e}_{\mathrm{aq}}^{-}$, and $\cdot \mathrm{H}$ radicals support the reduction from copper ion to copper as schematically illustrated in Fig. 6, while $\cdot \mathrm{OH}$ radical prevents the copper ion from reducing. For example, according to Buxton et al.,[25] the hydrate electron reacts rapidly with many species having more positive reduction potentials and its mode of reaction can be generally represented as one-electron transfer process: $e_{a q}^{-}+\mathrm{S}^{\mathrm{n}} \rightarrow \mathrm{S}^{\mathrm{n}-1}$, where $n$ is the positive charge on the solute. In contrast, the hydroxyl radical is a powerful oxidant, having a standard reduction potential and the reaction of . $\mathrm{OH}$ with ions is often represented as a simple electron transfer: $\cdot \mathrm{OH}+\mathrm{S}^{\mathrm{n}} \rightarrow \mathrm{S}^{\mathrm{n}+1}+\mathrm{OH}^{-}$, where $n$ is the charge on the ion. There are several reactions of $\cdot \mathrm{OH}$ reacting with inorganic ions. One of them is that $\cdot \mathrm{OH}$ abstracts $\mathrm{H}$ from a coordinated water molecule and followed by electron

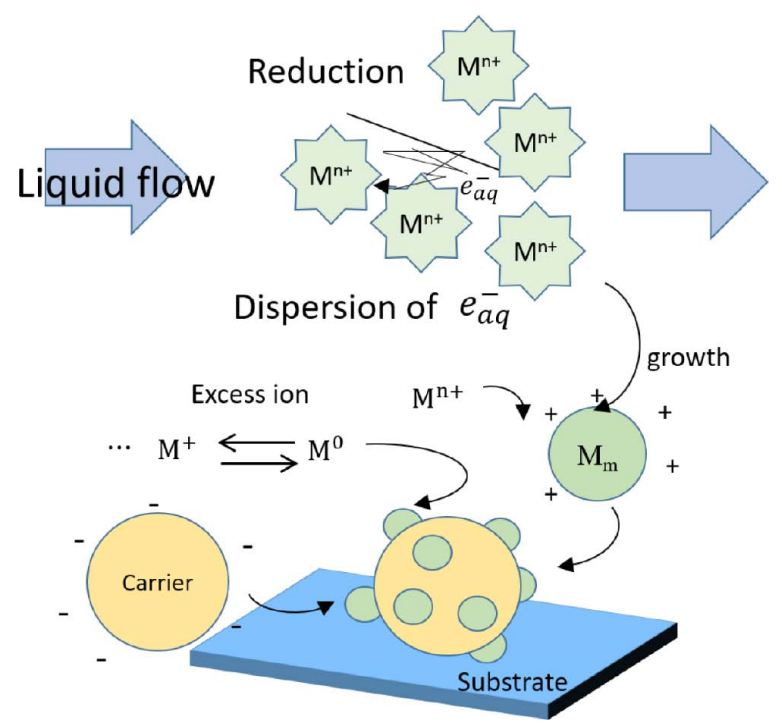

Fig. 6 Schematic diagram of particles synthesized in X-rayradiolysis-induced photochemical reaction in a flow channel.

transfer from the metal to the oxidized ligand: $. \mathrm{OH}+\mathrm{M}^{\mathrm{n}+} \mathrm{H}_{2} \mathrm{O} \rightarrow \mathrm{M}^{\mathrm{n}+} \mathrm{OH} \rightarrow \mathrm{M}^{(\mathrm{n}+1)+}+\mathrm{OH}^{-}$. Besides, the addition of methanol can provide the scavenger of the $\cdot \mathrm{OH}$ radical. According to Asmus et al.[24] and Ervens et al.,[26] in the case where methanol is added to the solution, the effects associated with proton and hydroxyl radicals reaction in the liquid solution can described as[23-26]

$$
\cdot \mathrm{OH}(\cdot \mathrm{H})+\mathrm{CH}_{3} \mathrm{OH} \rightarrow \mathrm{H}_{2} \mathrm{O}\left(\mathrm{H}_{2}\right)+\cdot \mathrm{CH}_{2} \mathrm{OH} .
$$

Then, the several candidates of associated reactions considered to be taken place in the mixed solution under the $\mathrm{X}$-ray irradiation, as follows:

$$
\begin{aligned}
& \mathrm{Cu}^{2+}+2 \mathrm{e}_{\mathrm{aq}}^{-} \rightarrow \mathrm{Cu} \\
& \mathrm{Cu}^{2+}+2 \cdot \mathrm{CH}_{2} \mathrm{O}+2\left(\mathrm{OH}^{-}\right) \rightarrow \mathrm{Cu}+2 \mathrm{HCOOH}+\mathrm{H}_{2} \\
& \mathrm{Cu}^{2+}+2\left(\mathrm{OH}^{-}\right) \rightarrow \mathrm{Cu}(\mathrm{OH})_{2} \\
& \mathrm{Cu}(\mathrm{OH})_{2} \rightarrow \mathrm{CuO}+\mathrm{H}_{2} \mathrm{O} \\
& \mathrm{Cu}(\mathrm{OH})_{2}+\mathrm{Cu} \rightarrow \mathrm{Cu}_{2} \mathrm{O}+\mathrm{H}_{2} \mathrm{O}
\end{aligned}
$$

Here, these copper and copper oxide particles are finally reduced and deposited onto the substrate. These reactions are dependent on chemical reaction rate, Arrhenius activation energy, and their concentrations. [25, 26]

In general, the nucleation of the particles are randomly occurred and grown up by X-ray irradiation, resulting the second aggregation and growth occur in their ripening process. The nucleation and initial growth process can be basically explained by the LaMer model.[27, 28] The nucleation and first growth time is determined by the radical ion distribution as shown in Fig. 6. When the X-ray radiolysis is induced by the X-ray irradiation, the radicals are nucleated at a spur and the spatial distribution length 
of radical dispersion is considered to be about a few $\mathrm{nm}$. [29] Around the spurs, particles are generated and grown under the influence of radicals and ions. Therefore, the nucleation and growth process are expected to be dependent of the liquid flow rate because the radical and ion concentration around the spurs are also influenced by the flow rate. There are two routes which copper or copper oxide particles are nucleated, grown, deposited and immobilized on the substrate. One is originated from the van der Waals attractive force working between the synthesized particles and substrate[28] as schematically shown in Fig. 6. Another is the reduction associated with the second electron generation from substrate by the X-ray irradiation as reported in the synthesis using electrochemical method.[30] As result, the growth or aggregation occurs at or near the surface of substrate. Therefore, in either case, the size and composition of synthesized particle are considered to be dependent on the flow rate because the radical distribution is modulated by the liquid flow rate. As the flow rate decreases, the concentration of $\cdot \mathrm{OH}$ trends to increase under the $\mathrm{X}$-ray radiolysis because the X-ray radiolysis continues to provide $\cdot \mathrm{OH}$ into the solution until the irradiation finishes. Then, the synthesized particles are more oxidized and their size increases with increasing the X-ray irradiation time. The behavior is in good agreement with our previous studies[11-14] performed using the X-ray irradiation cell without the fluidic channel. Consequently, the flow rate control enables us to control the deposition rate and composition.

Thus, at any rate, the X-ray radiolysis using SR enables to nucleate and grow these confection sugar like cupric particles directly from cupric acetate solution including an additive, methanol. In addition, in the lowest temperature and duration time, this technique can provide the $3 \mathrm{D}$ printing and additive manufacturing process using both plastic and metallic materials. For example, using a combination of fluidic channel on $x-y$ stage, X-ray radiolysis with a liquid slow system can provide the additive manufacturing with nano/micro-scale functional particles within the solution. As shown in our previous study,[11] the deposition of $\mathrm{Au}$ cluster aggregates with activity of SERS using X-ray radiolysis of commercial Au electroplating solution could be performed. The higher-order nanostructure consisting of Au-nanoparticles fabricated by using the X-ray radiolysis process enables the SERS sensor for a small amount of molecule.

\section{Conclusions}

This study demonstrated the deposition of copper oxide particles like confection sugar by X-ray radiolysis of the cupric acetate solution with the additive methanol. In this study, we fabricated the X-ray radiolysis system with a liquid flow channel. We investigated the elemental and composition analyses for the particles using SEM+EDX and micro-Raman spectroscopy. We found that the element components of the synthesized particles are diverse: $\mathrm{Cu}$, $\mathrm{Cu}_{2} \mathrm{O}, \mathrm{CuO}$, etc. The synthesized particle size increases with decreasing the flow rate. The flow rate dependence of the area ratio which is covered with the particles also show the same trend. These results are attributed to that the nucleation and growth process are strongly affected by the radical ion distributions around spurs where the ions are reacted. Consequently, the synthesis of particles are influenced by the liquid flow rate.

The direct X-ray irradiation using an SR source can provide an alternative route to explore the novel physical and chemical mechanism of liquid/solid interlayer reaction and applications for 3D printing technology and additive manufacturing.

\section{Acknowledgment}

This research and development work was supported by JSPS Grants-in-Aid for Scientific Research B (No. 17H02755).

\section{References}

[1] E. Sachs, M. Cima, P. Williams, D. Brancazio, and J. Cornie, "Three Dimensional Printing: Rapid Tooling and Prototypes Directly from a CAD Model,” J. Eng. Ind. Vol. 114, pp. 481-488, 1992; E. Sachs, M. Cima, J. Cornie, "Three-Dimensional Printing: Rapid Tooling and Prototypes Directly from CAD Model," CIRP Annals, Vol. 39, pp. 201-204, 1990.

[2] I. Gibson, D. Rosen, and B. Stucker, "Additive Manufacturing Technologies -3D Printing, Rapid Prototyping, and Direct Digital Manufaturing-," (Spinger, 2nd Edition, 2015).

[3] V. Saile, U. Wallradbe, O. Tabata, and J. G. Korvink, Advanced Micro and Nanosystems Vol. 7 "LIGA and its Applications,” (WILEY-VCH Verlag GmbH \& Co. KgaA, Weinheim, 2009).

[4] C. H. Bae, S. H. Nam, and S. M. Park, "Formation of silver nanoparticles by lase ablation of a silver target in $\mathrm{NaCl}$ solution,” Appl. Surf. Science, Vol. 197198, pp. 628-634, 2002. 
[5] K. Akamatsu, S. Ikeda, H. Nawafune, and H. Yanagimoto, "Direct Patterning of Copper on Polyimide Using Ion Exchangeable Surface Templates Generated by Site-Selective Surface Modification,” J. Am. Chem. Soc., Vol. 126, pp. 10822-10823, 2004.

[6] J. Bárta, M. Pospíšl, and V. Čuba, "Photo- and radiation-induced preparation of nanocrystalline copper and cuprous oxide catalysis,” J. Radioanal. Nucl. Chem., Vol. 286, pp. 611-618, 2010.

[7] Q. Ma, N. Moldovan, D. C. Mancini, and R. A. Rosenberg, "Synchrotron-radiation-induced, selective-area deposition of gold on polyimide from solution,” Applied Physics Letters, Vol. 76, No. 15, pp. 2014-2016, 2000.

[8] P. H. Borse, J. M. Yi, J. H. Je, W. L. Tsai, and Y. Hwu, " $p H$ dependence of synchrotron x-ray induced electroless nickel deposition,” Journal of Applied Physics, Vol. 95, No. 3, pp. 1166-1170, 2004.

[9] F. Karadas, G. Ertas, E. Ozkaraoglu, and S. Suzer, "X-ray-Induced Production of Golf Nanoparticles on $\mathrm{a} \mathrm{SiO}_{2} / \mathrm{Si}$ System and in a Poly (methyl methacrylate) Matrix,” Langmuir, Vol. 21, pp. 437-442, 2005.

[10] H. Oyanagi, Y. Orimoto, K. Hayakawa, K. Hatada, Z. Sun, L. Zhang, K. Tamashita, H. Nakamura, M. Uehara, A. Fukano, and H. Maeda, "Nanoclusters synthesized by synchrotron radiolysis in concert with wet chemistry," Scientific Reports, Vol. 4, article 7199, 2014.

[11] A. Yamaguchi, T. Matsumoto, I. Okada, I. Sakurai, and Y. Utsumi, "Surface-enhanced Raman scattering active gold nanostructure fabricated by photochemical reaction of synchrtron radiation," Mater. Chem. Phys., Vol. 160, pp. 205-211, 2015.

[12] A. Yamaguchi, I. Okada, T. Fukuoka, I. Sakurai, and Y. Utsumi, "Synthesis of metallic nanoparticles through X-ray radiolysis using synchrotron radiation,” Japanese Journal of Applied Physics, Vol. 55, No. 5, pp. 055502-1-055502-5, 2016.

[13] A. Yamaguchi, I. Okada, T. Fukuoka, M. Ishihara, I. Sakurai, and Y. Utsumi, "One-Step Synthesis of Copper and Cupric Oxide Particles from the Liquid Phase by X-Ray Radiolysis Using Synchrotron Radiation,” J. Nanomaterials, Article ID 8584304, 2016.

[14] A. Yamaguchi, T. Fukuoka, I. Okada, M. Ishihara, I. Sakurai, and Y. Utsumi, "Caltrop particles synthesized by photochemical reaction induced by X-ray radiolysis,” J. Synchrotron Rad., Vol. 24, pp. 653660, May 2017.
[15] A. Bhati, R. Bharwaj, A. K. Agrawal, N. Goyal, and S. Gautum, "Monochromatic X-ray Induced Novel Synthesic of Palsmonic Nanostructure for Photovoltaic Application,” Sci. Rep., Vol. 6, 22394, Apr. 2016.

[16] S. Remita, P. Fontaine, E. Lacaze, Y. Borensztein, H. Sellame, R. Farha, C. Rochas, and M. Goldmann, "X-ray radiolysis induced formation of silver nanoparticles: A SAXS and UV-visible absorption spectroscopy study,” Nucl. Instrum. Methods Phys. Res. Sect. B., Vol. 263, pp. 435-440, 2007.

[17] G. R. Dey, "Reduction of the copper ion to its metal and clusters in alcoholic media: A radiation chemical study,” Rad. Phys. Chem., Vol. 74, pp. 172-184, 2005.

[18] E. C. Le Ru and P. G. Etchegoin, Principles of Surface-Enhanced Raman Spectroscopy and Related Plasmonic Effects, Elsevier, Amsterdam, 2009.

[19] Q. Zhang, K. Zhang, D. Xu, G. Yang, H. Huang, F. Nie, C. Liu, and S. Yang, "CuO nanostructures: Synthesis, characterization, growth mechanisms, fundamental properties, and applications,” Prog. Mater. Sci., Vol. 60, pp. 208-337, 2014.

[20] D. P. Voltanti, D. Keyson, L. S. Cavalcante, A. Z. Simões, M. R. Joya, E. Longo, J. A. Varela, P. S. Pizani, and A. G. Souza, "Synthesis and characterization of $\mathrm{CuO}$ flower-nanostructure processing by a domestic hydrothermal microwave,” J. Alloy Compounds, Vol. 459, pp. 537-542, 2008.

[21] L. Debbichi, M. C. Marco De Lucas, J. F. Pierson, and $\mathrm{P}$. Krüger, "Vibrational properties of $\mathrm{CuO}$ and $\mathrm{Cu}_{4} \mathrm{O}_{3}$ from first-principles calculations, and raman and infrared spectroscopy," Journal of Physical Chemistry C, Vol. 116, No. 18, pp. 10232-10237, 2012.

[22] Image Proceesing and Analysis in Java, https:// imagej.nih.gov/ij/

[23] J. Weiss, "Radiochemistry of aqueous solutions," Nature, Vol. 153, pp. 748-750, 1944.

[24] K.-D. Asmus, H. Möckel, and A. Henglein, "Pulse Radiolytic Study of the Site of $\mathrm{OH}$ - Radical Attack on Appohatic Alcohols in Aqueous Solution,” J. Phys. Chem., Vol. 77, pp. 1218-1221, 1973.

[25] G. V. Buxton, C. L. Greenstock, W. P. Helman, and A. B. Ross, "Critical Review of rate constants for reactions of hydrated electrons, hydrogen atoms and hydroxyl radicals (.OH/.O-) in Aqueous Solution," Journal of Physical and Chemical Reference Data, Vol. 17, No. 2, p. 513, 19.

[26] B. Ervens, S. Gligorovski, and H. Herrmann, "Tem- 
perature-dependent rate constants for hydroxyl radical reactions with organic compounds in aqueous solutions,” Phys. Chem. Chem. Phys., Vol. 5, pp. 1811-1824, 2003.

[27] V. K. LaMer and R. H. Dinegar, "Theory, production and mechanism of formation of monodispersed hydrosols," Journal of the American Chemical Society, Vol. 72, No. 11, pp. 4847-4854, 1950.

[28] J. N. Israelacvili, Intermolecular and Surface Forces, Academic Press, London, UK, 3rd edition, 2011.

[29] H. Yamaguchi, Y. Uchihori, N. Yasuda, M. Takada, and H. Kitamura, "Estimation of Yields of $\mathrm{OH}$ Radicals in Water Irradiated by Ionizing Radiation,” J. Radiat. Rec., Vol. 46, pp. 333-341, 2005.
[30] A. Radl, D. Pradhan, Y. Sohn, and K. T. Leung, "Nanoscale Shape and Size Control of Cubin, Cuboctahedral, and Octhedral $\mathrm{Cu}-\mathrm{Cu}_{2} \mathrm{O}$ Core-Shell Nanoparticles on Si(100) by One-Step, Templateless, Capping-Agent-Free Electrodepostion,” ACS Nano, Vol. 4, pp. 1553-1560, 2010.

\author{
Shunya Saegusa \\ Ikuya Sakurai \\ Ikuo Okada \\ Takao Fukuoka \\ Satoru Suzuki \\ Yuichi Utsumi \\ Akinobu Yamaguchi
}

